\title{
DETERMINAN PROFITABILITAS \\ (STUDI PADA BANK UMUM KONVENSIONAL YANG TERDAFTAR DI BURSA EFEK INDONESIA TAHUN 2012-2016)
}

\author{
Solihin Sidik \\ Universitas Singaperbangsa Karawang \\ solihinsidik@yahoo.com
}

\begin{abstract}
ABSTRAK
Penelitian ini bertujuan untuk mengetahui, menjelaskan dan menganalisis tentang Profitabilitas, Capital Adequacy Ratio, Loan to Deposit Ratio, Beban Operasional terhadap Pendapatan Operasional dan Net Interest Margin pada Bank Umum Konvensional serta pengaruh parsial dan simultan CAR, LDR, BOPO dan NIM terhadap Profitabilitas Bank Umum Konvensional Periode 2012-2016. Jumlah sampel yang diambil 10 bank umum dengan asset terbesar pada periode penelitian teknik sampling jenuh. Penelitian ini diharapkan dapat memberikan sumbangan bagi pengembangan bidang manajemen khususnya manajemen keuangan. Metode penelitian yang digunakan penulis dalam penelitian ini menggunakan metode deskriptif dan verifikatif, dari hasil analisis data penelitian diperoleh beberapa kesimpulan sebagai berikut: (1) ROA Bank Umum konvensional selama periode penelitian memiliki rata-rata sebesar 2,46\% yaitu pada kategori sangat sehat.(2). Rasio CAR Bank Umum konvensional pada periode penelitian dengan rata-rata $17,34 \%$ dikategorikan sangat sehat. (3) Rasio LDR Bank Umum konvensional selama periode penelitian memiliki nilai rata-rata $89,31 \%$, dikategorikan cukup baik. (4) Rasio BOPO Bank Umum konvensional selama periode penelitian memiliki nilai mean 75,54\%, dikategorikan sangat sehat. (5) Rasio NIM Bank Umum konvensional selama periode penelitian memiliki nilai rata-rata 5,81\%, dikategorikan sangat sehat. (6) CAR secara parsial berpengaruh tidak signifikan dan berkontribusi negatif terhadap profitabilitas (ROA) Bank Umum konvensional pada periode penelitian dengan koefisien $-0,417$. Sedangkan LDR dan BOPO secara parsial berpengaruh negatif dan signifikan terhadap profitabilitas (ROA), dengan koefisien masing-masing -5,928 dan -3,871. BOPO merupakan variabel yang memiliki pengaruh paling besar terhadap Profitabilitas diantara Variabel lain. Sementara NIM secara parsial berpengaruh positif dan signifikan terhadap profitabilitas (ROA) dengan nilai koefisien 5,654. (7) CAR, LDR, BOPO dan NIM berpengaruh positif dan signifikan secara simultan terhadap Profitabilitas (ROA) Perbankan pada periode penelitian. Dengan koefisien 47,298
\end{abstract}

Kata Kunci: CAR, LDR, BOPO, NIM, Profitabilitas

\section{A. PENDAHULUAN}

Dunia perbankan adalah salah satu indikator pendukung pertumbuhan perekonomian dunia termasuk di indonesia. Seiring berjalannya waktu perbankan di Indonesia juga telah banyak mengalami perubahan yang signifikan. Hal tersebut karena dipengaruhi oleh beberapa faktor baik internal maupun eksternal. Faktor ekternal yang dapat mempengaruhi perbankan seperti sektor riil, politik, hukum, dan sosial. Dengan adanya kebijakan deregulasi dibidang perbankan pada tahun 1988 dimana pemerintah memberikan kemudahan untuk mendirikan bank cukup dengan menyetorkan modal sebesar 10 (sepuluh ) milyar rupiah, hal tersebut mengakibatkan semakin banyaknya bank baru yang bermunculan dengan berbagai jenis seperti bank umum konvensional dan bank syariah serta BPR Konvesional dan BPR Syariah.

Salah satu indikator yang digunakan untuk mengetahui profitabilitas adalah Return on Assets (ROA). Semakin besar Return on Assets (ROA) suatu bank maka semakin besar pula 
tingkat keuntungan yang dicapai bank tersebut, dan semakin baik pula posisi bank tersebut dari segi penggunaan asset. (Nur Mawadah, 2014). Berikut disajikan data empiris mengenai perkembangan Return On Asset (ROA) bank umum konvensional periode 2012-2016:

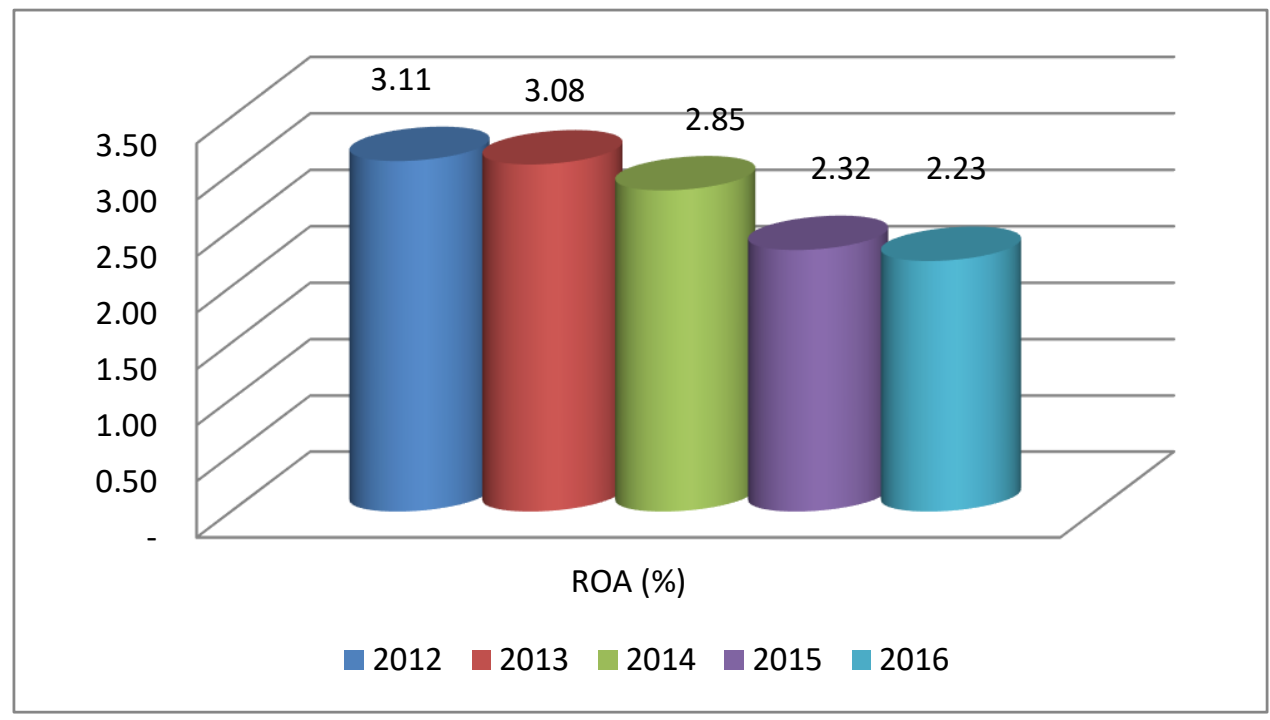

Sumber: Statistik perbankan Indonesia (diolah 2017)

\section{Gambar 1}

\section{Grafik Return On Asset (ROA)}

Rendahnya profitabilitas diduga karena adanya kenaikan Capital Adequacy Ratio (CAR). Menurut A.A Alit Wahyu Dwi Pranata (2015), CAR berpengaruh positif terhadap profitabilitas bank. Didukung oleh penelitian Syamsul Maryadi dan Agus Tribasuki (2014) menyatakan bahwa tingkat kecukupan modal (Capital Adequacy Ratio) berpengaruh positif dan signifikan terhadap kinerja keuangan. Serta Muh. Sabir. M, Muhammad Ali, Abd. Hamid Habbe (2012) dalam penelitiannya menyatakan bahwa CAR berpengaruh positif dan signifikan terhadap ROA. Menurut I Gusti Ayu Purnamawati (2014) dalam penelitiannya menyatakan bahwa $C A R$ have a positive and significant effect on profitability (ROA) on Conventional Rural Bank in Indonesia. Kemudian hasil penelitian Alindra Yanuardi, Djumilah Hadiwidjojo, Sumiati (2014) yang menyatakan bahwa CAR berpengaruh positif terhadap ROA, Data empiris Capital Adequacy Ratio pada bank umum konvensional tahun 2012-2016 disajikan dibawah ini :

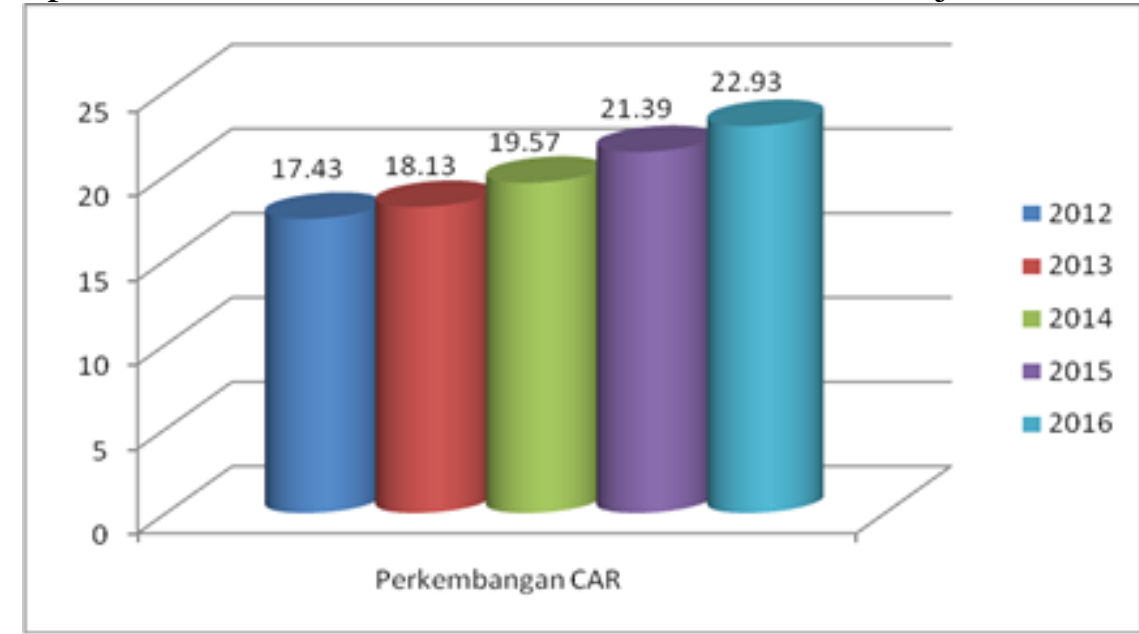

Sumber: Statistik perbankan Indonesia (diolah 2017)

Gambar 2

Grafik Capital Adequacy Ratio (CAR) 
Selain faktor Capital adequacy Ratio $(C A R)$ turunnya profitabilitas juga dapat diindikasikan oleh Loan to Deposit Ratio (LDR). Dalam penelitian Ni Made Inten Uthami Putri Warsa dan I Ketut Mustanda (2016), mengemukakan bahwa Loan to deposit ratio berpengaruh positif dan tidak signifikan terhadap return on assets, hal ini didukung oleh penelitian Samsul maryadi dan Agus tri basuki (2014) (Loan to Deposit Ratio) berpengaruh tidak signifikan terhadap kinerja keuangan. Kemudian I Gusti Ayu Purnamawati (2014) dalam penelitiannya menyatakan bahwa Liquidity Ratio (LDR) have a positive and significant effect on profitability (ROA) on Conventional Rural Bank in Indonesia. Berbeda dengan hasil penelitian Muh. Sabir. M, Muhammad Ali dan Abd. Hamid Habbe (2012) menyatakan bahwa LDR berpengaruh negatif dan signifikan terhadap ROA pada Bank Konvensional di Indonesia. Data empiris Loan To Deposit Ratio (LDR) pada bank umum konvensional tahun 2012-2016 disajikan dibawah ini:

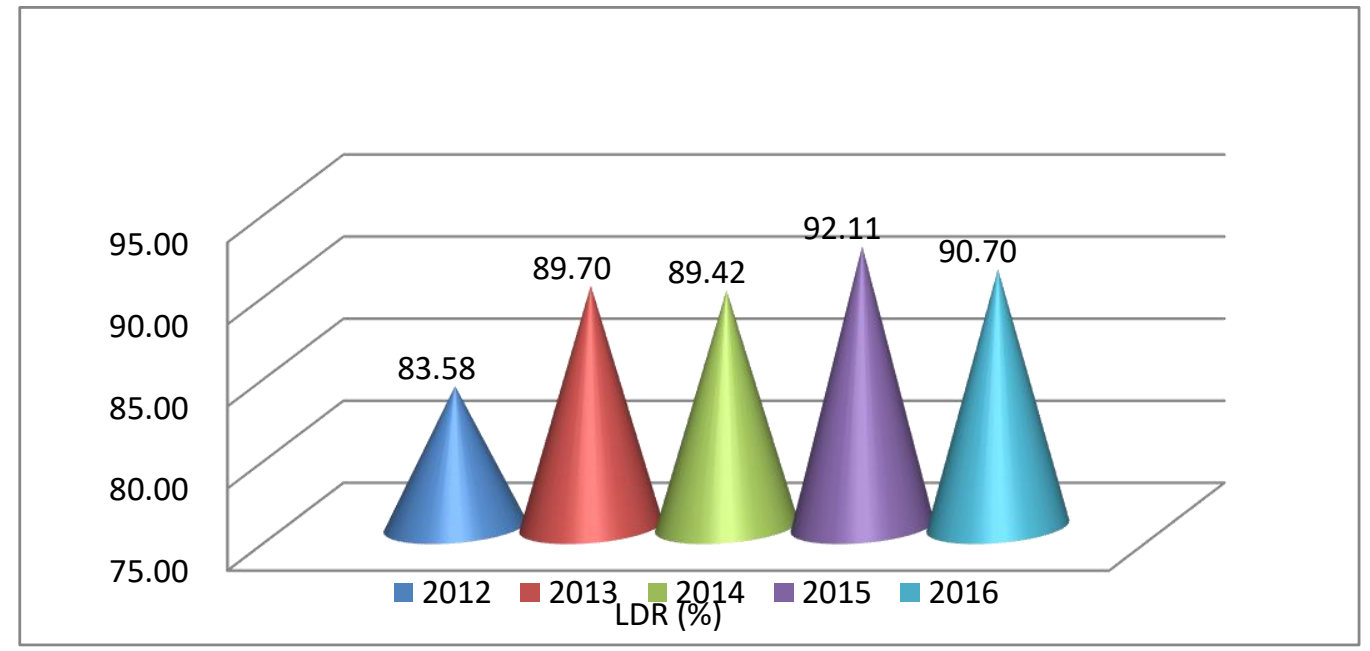

Sumber: Statistik perbankan Indonesia (diolah 2017)

\section{Gambar 3}

\section{Grafik Loan To Deposit Ratio (LDR)}

Faktor lain yang diidikasikan dapat mempengaruhi profitabilitas bank adalah tingkat effisiensi operasional bank yang dilihat dari rasio Biaya Operasional terhadap Pendapatan Operasional (BOPO) bank. Samsul Maryadi dan Agus tri Basuki, (2014) dalam penelitiannya menemukan adanya pengaruh negatif antara rasio BOPO dan Return On Asset. Data empiris Beban Operasional Terhadap Pendapatan Operasional (BOPO) pada bank umum konvensional tahun 2012-2016 disajikan dibawah ini:

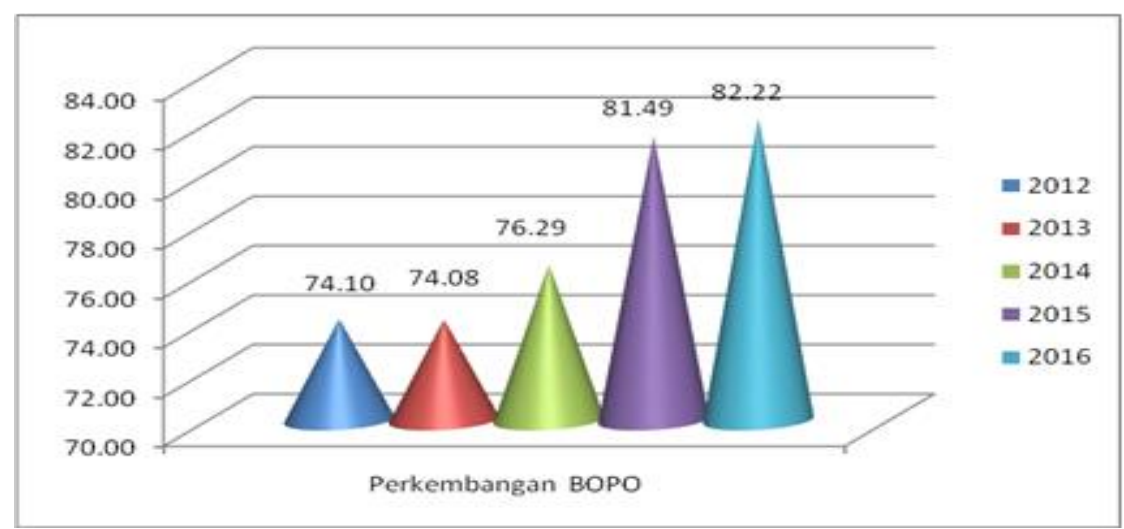

Sumber: Statistik perbankan Indonesia (diolah 2017)

Gambar 4

Grafik Beban Operasional Terhadap Pendapatan Operasional 
Selain ketiga faktor diatas yang dapat mempengaruhi profitabilitas terefleksi dari NIM (Net Interest Margin). Tan sau eng (2013) dalam penelitiannya menyatakan bahwa rasio Net Interest Margin mempunyai pengaruh yang signifikan dan berkontribusi paling besar terhadap Return On Asset. Kemudian diperkuat oleh penelitian Nur Hayati dan Musdholifah (2014) menyatakan bahwa Net Interest Margin berpengaruh terhadap profitabilitas. Berikut adalah data empiris Net Interest Margin perbankan umum konvesional periode 2012-2016.

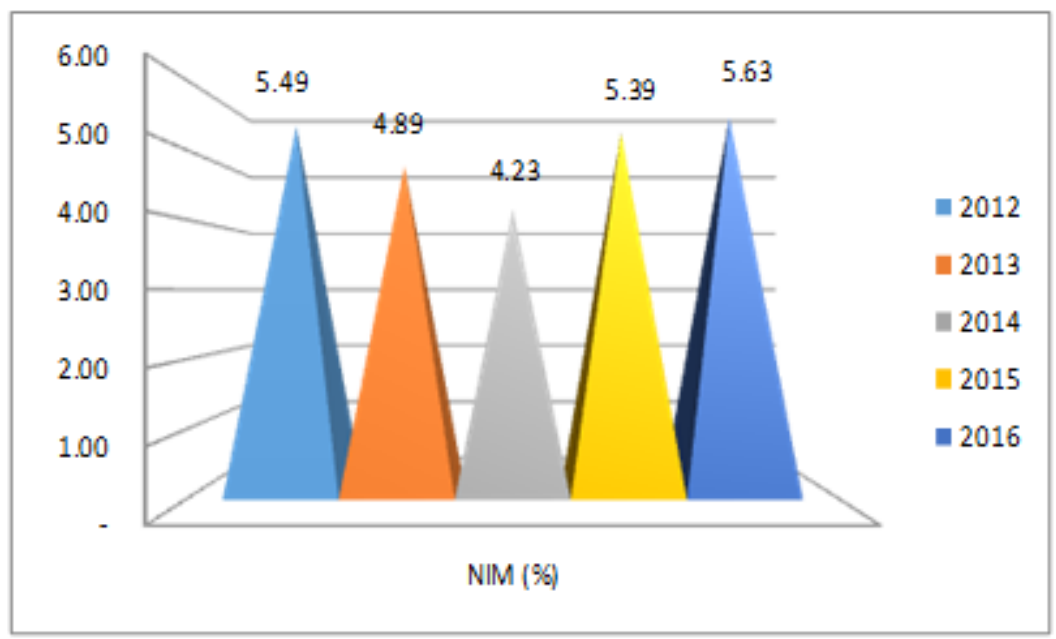

Sumber : Statistik perbankan Indonesia (diolah 2017)

Gambar 5

Grafik Net Interest Margin

Berdasarkan uraian latar belakang sebagaimana tersebut di atas, serta melihat fenomena rasio Return On Asset (ROA), Capital Adequacy Ratio (CAR), Loan to Deposit Ratio (LDR), Beban Operasional Terhadap Pendapatan Operasional (BOPO) dan Net Interest Margin (NIM) yang tidak menentu selama periode lima tahun (2012 hingga 2016), maka perlu diajukan penelitian untuk menganalisis apakah terdapat pengaruh Capital Adequacy Ratio (CAR), Loan to Deposit Ratio (LDR), Beban Operasional Terhadap Pendapatan Operasional (BOPO) dan Net Interest Margin (NIM) terhadap Profitabilitas yang diproksikan dengan Return On Asset (ROA).

\section{B. KAJIAN PUSTAKA \\ Profitabilitas}

Menurut Sartono (2008:122), menyatakan bahwa rasio profitabilitas adalah kemampuan perusahaan memperoleh laba dalam hubungannya dengan penjualan, total aktiva maupun modal sendiri. Menurut Sugiono dan Untung, (2008:70) ada beberapa rasio profitabilitas yang dapat digunakan, diantaranya adalah Gross Profit Margin, Net Profit Margin, Cash Flow Margin, Return On Asset dan Return On Equity. Menurut Rachmat Firdaus dan Maya Ariyanti (2011:217) "Rasio profitabilitas bertujuan untuk mengukur kemampuan suatu perusahaan dalam memperoleh keuntungan (laba)". Ukuran rasio profitabilitas diproyeksikan dengan rasio Return On Assets (ROA), ROA mengukur kemampuan perusahaan untuk memperoleh earning, ROA juga dapat mengukur pertumbuhan suatu usaha keuangan. Menurut Rachmat Firdaus dan Maya Ariyanti (2011:223) menyatakan bahwa "Return On Asset menunjukan seberapa persen laba yang diperoleh dari setiap dana, baik yang berasal dari pinjaman-pinjaman (modal luar) maupun dana sendiri/modal sendiri yang ditanamkan dalam aktiva perusahaan". Sedangkan menurut Riyanto (2008:336), menyatakan bahwa "ROA adalah kemampuan dari modal yang diivestasikan dalam keseluruhan aktiva untuk menghasilkan keuntungan neto". Menurut 
Dendawijaya (2009:118) menyatakan bahwa "ROA digunakan untuk mengukur kemampuan bank dalam memperoleh laba secara keseluruhan dari total aktiva yang dimiliki. Menurut Surat Edaran Otoritas Jasa Keuangan Nomor 11/Seojk.03/2015 bahwa "Return On Asset (ROA) dihitung dengan cara membagi laba sebelum pajak disetahunkan dengan rata-rata total asset". Adapun Formula yang bisa digunakan dalam menghitung rasio Return on asset (ROA) adalah sebagai berikut:

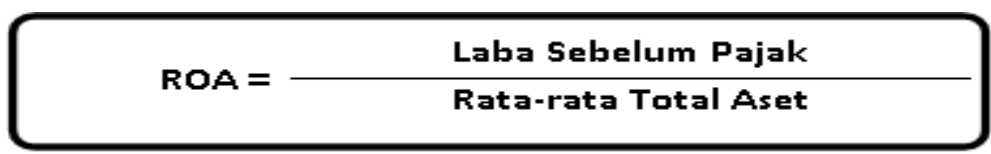

Sedangkan predikat bank berdasarkan ROA disajikan pada tabel dibawah ini:

\section{Tabel 1}

Predikat Bank Berdasarkan ROA

\begin{tabular}{|l|l|l|}
\hline No & \multicolumn{1}{|c|}{ Rasio } & \multicolumn{1}{|c|}{ Predikat } \\
\hline 1 & $2 \%<\mathrm{ROA}$ & Sangat Sehat \\
\hline 2 & $1,25 \%<\mathrm{ROA} \leq 2 \%$ & Sehat \\
\hline 3 & $0,5 \%<\mathrm{ROA} \leq 1,25 \%$ & Cukup Sehat \\
\hline 4 & $0 \%<\mathrm{ROA} \leq 0,5 \%$ & Kurang Sehat \\
\hline 5 & ROA $\leq 0 \%$ & Tidak Sehat \\
\hline
\end{tabular}

Sumber: Kodifikasi penilaian kesehatan bank

\section{Capital Adequacy Ratio}

Menurut ismail (2015:124) "Ekuitas disebut juga modal adalah dana yang diinvestasikan oleh pemilik dalam rangka pendirian badan usaha untuk membiayai kegiatan usaha bank dan untuk memenuhi regulasi pemerintah". Sedangkan menurut taswan (2013:139) "modal bank adalah dana yang diinvestasikan oleh pemilik dalam rangka pendirian badan usaha yang dimaksudkan untuk membiayai kegiatan usaha bank di samping untuk memenuhi regulasi yang ditetapkan oleh otoritas moneter". Menurut Ismail (2015:124) "Perhitungan CAR adalah menghitung perbandingan antara modal bank terhadap aktiva tertimbang menurut resiko". Perhitungan Capital Adequacy Ratio (CAR) secara umum dilakukan berdsarkan prinsip-prinsip yang ditetapkan oleh Bank For Internasional Settlement (BIS). Formula perhitungan CAR adalah sebagai berikut:

$$
\text { CAR }=\frac{\text { Modal }}{A T M R}
$$

Adapun predikat kesehatan bank berdasarkan Capital Adequacy Ratio adalah sebagai berikut:

\section{Tabel 2}

Predikat Capital Adequacy Ratio

\begin{tabular}{|c|c|c|}
\hline No & Rasio & Predikat \\
\hline 1 & $12 \%<\mathrm{CAR}$ & Sangat Sehat \\
\hline 2 & $9 \%<\mathrm{CAR} \leq 12 \%$ & Sehat \\
\hline 3 & $8 \%<\mathrm{CAR} \leq 9 \%$ & Cukup Sehat \\
\hline 4 & $6 \%<\mathrm{CAR} \leq 8 \%$ & Kurang Sehat \\
\hline 5 & $\mathrm{CAR} \leq 6 \%$ & Tidak Sehat \\
\hline
\end{tabular}

Sumber: Kodifikasi Kesehatan Bank

\section{Loan To Deposit Ratio}


Menurut Kamaludin (2011:41) "Rasio likuiditas menunjukan tingkat kemudahan relatif suatu aktiva untuk segera dikonversikan kedalam kas dengan sedikit atau tanpa penurunan nilai, serta tingkat kepastian tentang jumlah kas yang dapat diperoleh". Loan To Deposit Ratio (LDR) yang mengukur besarnya dana yang ditempatkan dalam bentuk kredit yang berasal dari dana yang dikumpulkan oleh bank terutama masyarakat. Menurut Kasmir, (2012:290) menyatakan bahwa "LDR merupakan salah satu rasio likuiditas yang sering dipakai untuk mengukur kinerja bank. LDR mengukur volume kredit yang disalurkan oleh bank dibandingkan dengan jumlah dana yang berhasil dihimpun oleh bank". Sedangkan menurut Dendawijaya (2009) menyatakan apabila hasil pengukuran jauh diatas target dan batasnya berarti tidak tertutup kemungkinan bank akan mengalami kesulitan likuiditas yang pada gilirannya akan menimbulkan tekanan pada pendapatan bank. Taswan (2013:63) perhitungan Loan To Deposit Ratio (LDR) membagi kredit yang diberikan kepada pihak ketiga (tidak termasuk kredit kepada bank lain) dengan dana pihak ketiga mencakup giro, tabungan, deposito (tidak termasuk giro dan deposito antar bank).

Adapun formula yang digunakan dalam menentukan besarnya Loan to Deposit Ratio (LDR) adalah sebagai berikut:

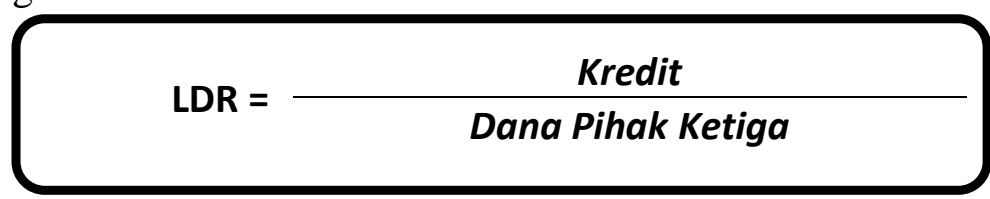

Sedangkan predikat kesehatan bank berdasarkan Loan to Deposit Ratio adalah sebagai berikut:

Table 3

Predikat Loan to Deposit Ratio

\begin{tabular}{|l|l|l|}
\hline No & \multicolumn{1}{|c|}{ Rasio } & \multicolumn{1}{|c|}{ Predikat } \\
\hline 1 & $50 \%<\mathrm{LDR} \leq 75 \%$ & Sangat Baik \\
\hline 2 & $75 \%<\mathrm{LDR} \leq 85 \%$ & Baik \\
\hline 3 & $85 \%<\mathrm{LDR} \leq 100 \%$ & Cukup Baik \\
\hline 4 & $100 \%<\mathrm{LDR} \leq 120 \%$ & Kurang Baik \\
\hline 5 & LDR $>120 \%$ & Tidak Baik \\
\hline
\end{tabular}

Sumber: SE/BI/ No 6 DPNP/2004

\section{BOPO}

Menurut Dendawijaya (2009:123) BOPO "merupakan rasio biaya operasional digunakan untuk mengukur tingkat efisiensi dan kemampuan bank dalam melakukan kegiatan operasinya". Menurut Taswan (2010:167) "BOPO mengindikasikan efisiensi operasional bank". Efisiensi industri perbankan dapat ditinjau dari sudut pandang mikro maupun makro. Menurut Surat Edaran Bank Indonesia Surat Edaran Otoritas Jasa Keuangan Nomor 11/Seojk.03/2015 Biaya Operasional terhadap Perndapatan Operasional (BOPO) adalah beban operasi terhadap pendapatan operasi dengan angka yang dihitung per posisi (tidak disetahunkan).

Adapun formula yang bisa digunakan untuk menghitung rasio BOPO adalah sebagai berikut:

$$
\text { BOPO }=\frac{\text { Total Beban Operasional }}{\text { Total Pendapatan Operasional }}
$$

Sedangkan predikat kesehatan bank berdasarkan BOPO disajikan pada tabel dibawah ini:

\section{Tabel 4}




\section{Net Interest Margin}

\begin{tabular}{|l|c|}
\hline \multicolumn{1}{|c|}{ Rasio } & Peringkat \\
\hline $\mathrm{BOPO} \leq 94 \%$ & Sangat Sehat \\
\hline $94 \%<\mathrm{BOPO} \leq$ & Sehat \\
$95 \%$ & \\
\hline $95 \%<\mathrm{BOPO} \leq$ & Cukup Sehat \\
$96 \%$ & \\
\hline $96 \%<\mathrm{BOPO} \leq$ & Kurang Sehat \\
$97 \%$ & \\
\hline BOPO $>97 \%$ & Tidak Sehat \\
\hline
\end{tabular}

Sumber: SE BI No. 6/23/DPNP tahun 2004

Pengertian Net Interest Margin (NIM) menurut Surat Edaran Otoritas Jasa Keuangan Nomor 11/Seojk.03/2015 adalah sebagai berikut :"Net Interest Margin (NIM) merupakan perbandingan antara pendapatan bunga bersih terhadap rata-rata aktiva produktifnya adapun Pendapatan bunga bersih adalah pendapatan bunga dikurangi dengan beban bunga (disetahunkan)". Menurut Selamet Riyadi (2006:21) adalah sebagai berikut : "Net Interest Margin (NIM) merupakan perbandingan antara presentase hasil bunga terhadap total asset atau terhadap total earning assets." Taswan (2013:63) "perhitungan Net Interest Margin (NIM) dengan cara membagi antara pendapatan Bunga bersih dengan rata-rata aktiva produktif". Adapun formula yang digunakan dalam menentukan besarnya Loan to Deposit Ratio (LDR) adalah sebagai berikut:

\section{$N I M=$ Pendapatan Bunga Bersih \\ Rata-rata Aktiva Produktif}

Sedangkan predikat kesehatan bank berdasarkan Net Interest Margin disajikan pada tabel dibawah ini:

\section{Tabel 5}

Predikat Net Interest Margin

\begin{tabular}{|c|c|c|}
\hline No & Rasio & Predikat \\
\hline 1 & $3 \%<\mathrm{NIM}$ & Sangat Sehat \\
\hline 2 & $2 \%<\mathrm{NIM} \leq 3 \%$ & Sehat \\
\hline 3 & $1,5 \%<\mathrm{NIM} \leq 2 \%$ & Cukup Sehat \\
\hline 4 & $1 \%<\mathrm{NIM} \leq 1,5 \%$ & Kurang Sehat \\
\hline 5 & NIM $\leq 1 \%$ & Tidak Sehat \\
\hline
\end{tabular}

Sumber: Kodifikasi Penilaian Kesehatan Bank

\section{Hipotesis Penelitian}

Berdasarkan uraian mengenai landasan teori hasil penelitian dan kerangka pemikiran diatas, maka hipotesis yang diajukan adalah:

1. Terdapat pengaruh antara Capital Adequacy Ratio (CAR) terhadap Profitabilitas

2. Terdapat Pengaruh antara Loan To Deposit Ratio (LDR) terhadap Profitabilitas

3. Terdapat pengaruh antara Beban Operasional Terhadap Pendapatan Operasional (BOPO) terhadap Profitabilitas

4. Terdapat pengaruh Net Interest Margin (NIM) terhadap Profitabilitas

5. Terdapat pengaruh antara Capital Adequacy Ratio, Loan To Deposit Ratio, Beban Operasional Terhadap Pendapatan Operasional dan Net Interest Margin terhadap Profitabilitas 


\section{METODE PENELITIAN DAN ANALISIS DATA}

Metode penelitian pada dasarnya merupakan cara ilmiah untuk mendapatkan data dengan tujuan dan kegunaan tertentu. Cara ilmiah kegiatan penelitian itu didasarkan pada ciri-ciri keilmuan, yaitu rasional, empiris, dan sistematis (Sugiyono 2012:2). Dalam penelitian ini menggunakan metode penelitian deskriptif dan verifikatif. Menurut Sugiyono (2012:35), penelitian deskriptif adalah penelitian yang dilakukan untuk mengetahui nilai variabel mandiri, baik satu variabel atau lebih (independent) tanpa membuat perbandingan atau menghubungkan dengan variabel yang lain. Penelitian verifikatif menurut Sugiyono (2012:3) bahwa metode penelitian kuantitatif yang digunakan untuk penelitian populasi atau sampel tertentu, dan analisis data bersifat statistik dengan tujuan untuk menguji hipotesis yang telah ditetapkan. Penelitian ini merupakan penelitian mengenai determinan profitabilitas (studi pada bank umum konvensional yang terdaftar di bursa efek Indonesia tahun 2012-2016). Penelitian ini dimulai dengan menggunakan analisis Capital Adequacy Ratio (CAR) sebagai variabel $\mathrm{X}_{1}$. Kemudian indikator Loan To Deposit Ratio (LDR) sebagai variabel $\mathrm{X}_{2}$. Selanjutnya indikator Beban Operasional Terhadap Pendapatan Operasional (BOPO) sebagai variable $\mathrm{X}_{3}$. Kemudian indkator Net Interest Margin (NIM) sebagai $\mathrm{X}_{4}$ Dan terakhir menggunakan analisis Profitabilitas yang diproksikan dengan Return On Asset (ROA) sebagai variabel Y.

\section{Populasi}

Sugiyono (2011:80), Populasi adalah wilayah generalisasi yang terdiri atas objek atau subjek yang mempunyai kualitas dan karakteristik tertentu yang ditetapkan oleh peneliti untuk dipelajari dan kemudian ditarik kesimpulannya. Populasi dalam penelitian ini yang digunakan adalah sepuluh bank umum konvensional yang memiliki asset terbesar pada periode penelitian

\section{Sampel}

Penelitian ini menggunakan data sekunder yaitu data yang telah dikumpulkan oleh lembaga pengumpul data dan dipublikasikan kepada masyarakat pengguna data. Data sekunder berupa Laporan keuangan tahunan (annual report) yang dipublikasikan bank. Pengambilan sampel menggunakan metode sampling jenuh dari sepuluh bank dengan asset terbesar, dikarenakan populasi yang akan diteliti kurang dari 30. Maka seluruh populasi dapat dijadikan sampel (Riduan 2010:21). Jadi dalam penelitian ini sampelnya adalah sepuluh (10) bank. Untuk lebih jelasnya dapat terlihat dari tabel 3.2 berikut ini:

\section{Tabel 6}

Daftar Bank Dengan Aset Terbesar yang terdaftar di BEI Menurut OJK Tahun 2016

\begin{tabular}{|r|l|l|}
\hline No & \multicolumn{1}{|c|}{ Nama Bank } & $\begin{array}{c}\text { Aset (dalam Jutaan } \\
\text { Rupiah) }\end{array}$ \\
\hline 1 & PT Bank Rakyat Indonesia (Persero) Tbk & 872.969 .884 \\
\hline 2 & PT Bank Mandiri (Persero), Tbk & 858.895 .923 \\
\hline 3 & PT Bank Central Asia, Tbk & 612.971 .304 \\
\hline 4 & PT Bank Negara Indonesia (Persero), Tbk & 504.631 .660 \\
\hline 5 & PT Bank CIMB Niaga, Tbk & 233.539 .932 \\
\hline 6 & PT Bank Tabungan Negara (Persero), Tbk & 189.513 .532 \\
\hline 7 & PT Bank Pan Indonesia, Tbk & 177.420 .647 \\
\hline 8 & PT Maybank Indonesia, Tbk & 151.385 .764 \\
\hline 9 & PT Bank Danamon Indonesia, Tbk & 145.083 .665 \\
\hline 10 & PT Bank OCBC NISP, Tbk & 128.948 .060 \\
\hline
\end{tabular}

Sumber: Laporan Keuangan Bank. www.ojk.go.id. (diolah 2017) 
Persamaan Regresi Linier Berganda

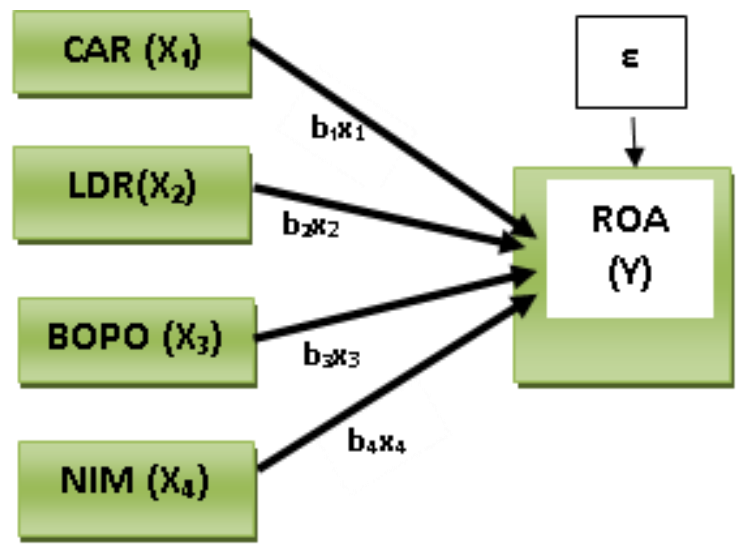

Gambar 6

Analisis Regresi Linier Berganda

Persamaan Struktural :

$\mathbf{Y}=\alpha+b_{1} X_{1}+b_{2} X_{2}+b_{3} X_{3}+b_{4} X_{4}+\dot{\varepsilon}$

Keterangan:

$\mathrm{Y}=$ Profitabilitas (ROA)

$\alpha=$ Konstanta

$\mathrm{X}_{1} \quad=$ Capital Adequacy Ratio

$\mathrm{X}_{2} \quad=$ Loan to Deposit Ratio

$\mathrm{X}_{3}=\mathrm{BOPO}$

$\mathrm{X}_{4} \quad=$ Net Interest Margin

$\mathrm{b}_{1}-\mathrm{b}_{4}=$ Koefisien Determinasi

$\dot{\varepsilon}=$ Standard Error Of The Estimate

D. HASIL PENELITIAN

Pengujian Keabsahan Data

Uji Normalitas

Uji normalitas digunakan untuk mengetahui apakah suatu data mengikuti sebaran normal atau tidak. Pengujian dilakukan dengan menggunakan metode Kolmogorov-Smirnov. Dengan ketentuan apabila variabel memiliki nilai $\alpha$ hitung $>0,05$ maka variabel tersebut terdistribusi normal. 
Tabel 7

Hasil Uji Normalitas

One-Sample Kolmogorov-Smirnov Test

\begin{tabular}{|ll|r|}
\hline & & $\begin{array}{c}\text { Unstandardized } \\
\text { Residual }\end{array}$ \\
\hline $\mathrm{N}$ & Mean & 50 \\
& & .0000000 \\
& Std. Deviation & .51633881 \\
Most Extreme Differences & Absolute & .122 \\
& Positive & .076 \\
& Negative & -.122 \\
Kolmogorov-Smirnov Z & & .866 \\
Asymp. Sig. (2-tailed) & & .441 \\
\hline
\end{tabular}

a. Test distribution is Normal.

Sumber: SPSS 22 (data diolah 2017)

Tabel di atas dapat diketahui bahwa nilai signifikansi sebesar 0.441 lebih besar dari 0,05 , sehingga dapat disimpulkan bahwa data yang diuji terdistribusi normal.

\section{Uji Multikolinearitas}

Model korelasi yang baik seharusnya tidak terjadi korelasi di antara variabel independen. Jika variabel independen saling berkorelasi maka variabel ini tidak ontogonal. Variabel ontogonal adalah variabel independen yang nilai korelasi antar sesama variabel independen sama dengan nol.

Untuk mendeteksi adanya multikolonieritas dengan membuat hipotesis:

a. Tolerance value $<0,10$ atau VIF $>10$ : terjadi multikolinearitas

b. Tolerance value $>0,10$ atau VIF $<10$ : tidak terjadi multikolinearitas

Table 8

Hasil Uji Multikolinearitas

\begin{tabular}{|c|c|c|c|}
\hline \multirow{2}{*}{\multicolumn{2}{|c|}{ Model }} & \multicolumn{2}{|c|}{ Collinearity Statistics } \\
\hline & & Tolerance & VIF \\
\hline \multirow[t]{5}{*}{1} & (Constant) & & \\
\hline & CAR & .763 & 1.311 \\
\hline & LDR & .752 & 1.329 \\
\hline & BOPO & .684 & 1.461 \\
\hline & NIM & .683 & 1.465 \\
\hline
\end{tabular}

a. Dependent Variable: ROA

Sumber: SPSS 22 (data diolah 2017)

Berdasarkan Tabel dapat ditarik kesimpulan bahwa nilai Tolerance dan VIF terlihat bahwa tidak ada nilai Tolerance di bawah 0.10 dan nilai VIF tidak ada di atas 10 hal ini berarti keempat variabel independen tersebut tidak terdapat hubungan multikolinieritas sehingga dapat digunakan untuk memprediksi profitabilitas yang diproksikan dengan Return On Asset (ROA) selama periode penelitian yaitu 2012 sampai dengan 2016. 


\section{Uji Heteroskedastisitas}

Heteroskedastisitas adalah keadaan dimana terjadi ketidaksamaan varian dari residual untuk semua pengamatan pada model regresi. Prasyarat dalam model regresi adalah tidak adanya masalah heteroskedastisitas. Uji heterokedastisitas bertujuan menguji apakah dalam model regresi terjadi ketidaksamaan variance dari residual satu pengamatan ke pengamatan yang lain Pengujian pada penelitian ini menggunakan Grafik scatterplot antara nilai prediksi variabel dependen yaitu ZPRED dengan residualnya SRESID. Tidak terjadi heteroskedastisitas apabila tidak ada pola yang jelas, serta titik-titik menyebar di atas dan di bawah angka 0 pada sumbu Y

\section{Scatterplot}

\section{Dependent Variable: ROA}

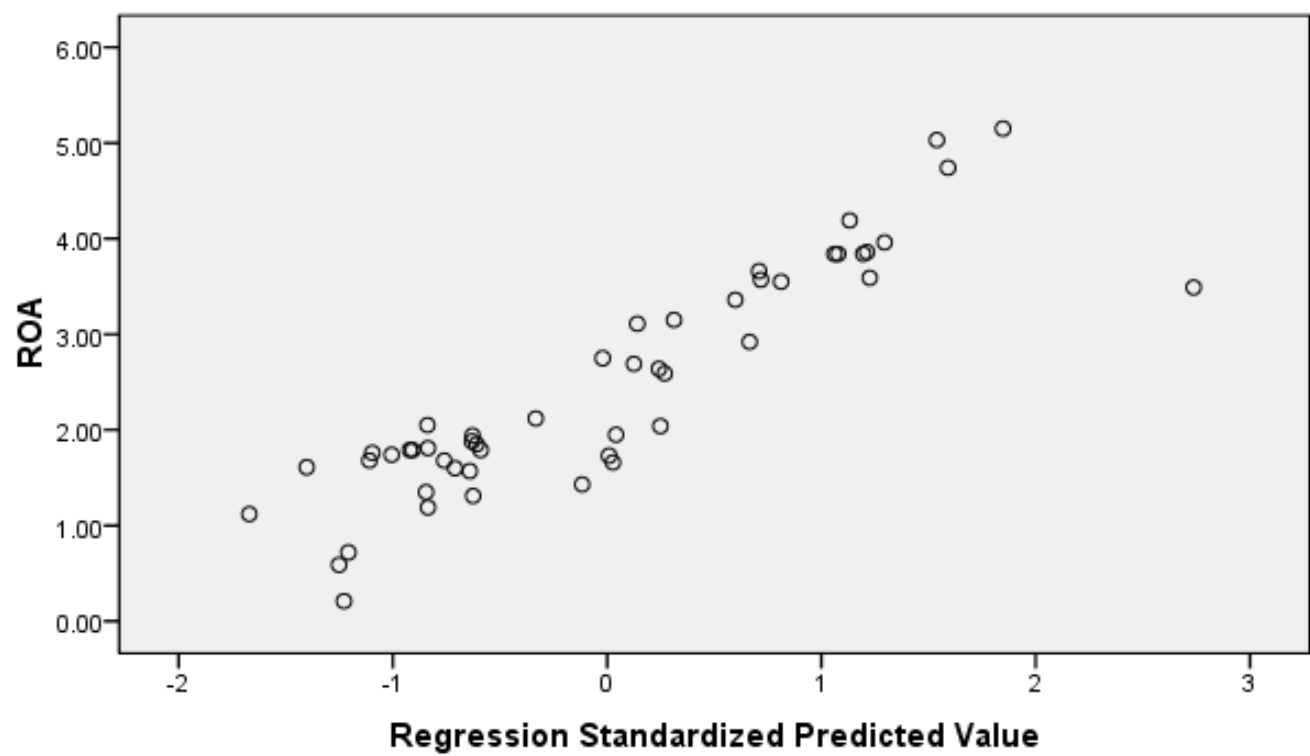

Gambar 7

Hasil Uji Heteroskedastisitas

Sumber: SPSS 22 (data diolah 2017)

Berdasarkan gambar diatas dapat diketahui bahwa data tersebut yang ditunjukan melalui titiktitik tidak berkumpul pada satu tempat serta tidak membentuk suatu pola tertentu, tetapi menyebar secara merata diatas dan dibawah garis nol sehingga dapat disimpulkan bahwa pada uji regresi ini tidak terdapat masalah heteroskedastisitas.

\section{Uji Autokorelasi}

Autokorelasi adalah keadaan dimana terjadinya korelasi antara residual pada satu pengamatan dengan pengamatan lain pada model regresi. Metode pengujian menggunakan uji DurbinWatson (uji DW) dengan ketentuan sebagai berikut:

a. Jika d lebih kecil dari dl atau lebih besar dari 4-dl, maka hipotesis nol ditolak, yang berarti terdapat autokorelasi.

b. Jika d terletak antara du dan 4-du, maka hipotesis nol diterima yang berarti tidak ada autokorelasi. 
c. Jika d terletak antara dl dan du atau 4-du dan 4-dl, maka tidak menghasilkan kesimpulan yang pasti.

Tabel 9

Hasil Uji Autokorelasi

Model Summary ${ }^{b}$

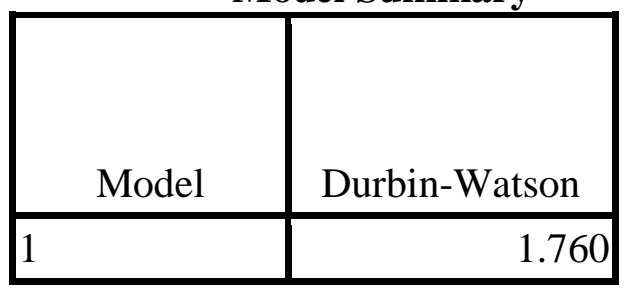

BOPO

a. Predictors: (Constant), NIM, LDR, CAR,

b. Dependent Variable: ROA

Sumber: SPSS 22 (data diolah 2017)

Berdasarkan data output diatas dapat diketahui bahwa nilai DW sebesar 1,760, selanjutnya nilai ini dibandingkan dengan nilai tabel (tabel Durbin Watson) signifikansi 5\%, dimana jumlah sample $(\mathrm{N}=50)$ dan jumlah variable independent $(\mathrm{K}=4)$ maka diperoleh nilai du 1,721. Nilai DW 1,760 lebih besar dari batas atas du yaitu 1,721 dan kurang dari (4-du) 4-1,760 = 2,240. Maka dapat disimpulkan bahwa tidak terdapat autokorelasi.

\section{E. PEMBAHASAN HASIL PENELITIAN}

\section{Analisis Regresi Linier Berganda}

Berdasarkan hasil pengolahan data dengan regresi linier berganda menggunakan software SPSS 22, diperoleh koefisien untuk setiap variable Capital Adequacy Ratio $\left(\mathrm{X}_{1}\right)$, Loan To Deposit Ratio $\left(\mathrm{X}_{2}\right)$, Beban Operasional terhadap pendapatan operasional $\left(\mathrm{X}_{3}\right)$ dan Net Interest Margin $\left(\mathrm{X}_{4}\right)$ terhadap Profitabilitas $(\mathrm{Y})$. Hasil analisis tersebut dapat dilihat pada tabel 4.5 dibawah ini.

\section{Table 10}


Hasil uji regresi Linier bergandaCoefficients ${ }^{\mathrm{a}}$

\begin{tabular}{|c|c|c|c|c|c|c|}
\hline \multirow[b]{2}{*}{ Mod } & & \multicolumn{2}{|c|}{$\begin{array}{c}\text { Unstandardized } \\
\text { Coefficients }\end{array}$} & \multirow{2}{*}{$\begin{array}{c}\text { Standardized } \\
\text { Coefficients } \\
\text { Beta }\end{array}$} & \multirow[b]{2}{*}{$\mathrm{t}$} & \multirow[b]{2}{*}{ Sig. } \\
\hline & & B & $\begin{array}{l}\text { Std. } \\
\text { Error }\end{array}$ & & & \\
\hline \multirow[t]{5}{*}{1} & $\begin{array}{l}(\text { Cons } \\
\operatorname{tant})\end{array}$ & 7.092 & .986 & & 7.193 & .000 \\
\hline & CAR & -.016 & .038 & -.031 & -.417 & .679 \\
\hline & LDR & -.040 & .010 & -.292 & -3.871 & .000 \\
\hline & $\begin{array}{l}\text { BOP } \\
\text { O }\end{array}$ & -.039 & .007 & -.468 & -5.928 & .000 \\
\hline & NIM & .371 & .066 & .447 & 5.654 & .000 \\
\hline
\end{tabular}

a. Dependent Variable: ROA

Sumber: SPSS 22 (data diolah 2017)

Analisis regresi linear berganda digunakan untuk menguji pengaruh dua atau lebih variabel independen terhadap satu variabel dependen. Persamaan regresi dapat dilihat dari tabel hasil uji coefficients. Pada tabel coefficients yang dibaca adalah nilai dalam kolom $\mathrm{B}$, baris pertama menunjukkan konstanta (a) dan baris selanjutnya menunjukkan konstanta variabel independen. Berdasarkan tabel di atas maka model regresi yang digunakan adalah sebagai berikut.

$$
Y=7,092-0.16 X_{1}-0,040 X_{2}-0,39 X_{3}+0,371 X_{4}+\varepsilon
$$

Berdasarkan model regresi dan tabel 4.5 di atas maka hasil regresi berganda dapat dijelaskan sebagai berikut

1. Persamaan regresi linear berganda diketahui mempunyai konstanta sebesar 7,092 dengan arah positif. Sehingga besaran konstanta menunjukkan bahwa jika variabel-variabel independen (CAR, LDR, BOPO dan NIM) diasumsikan konstan, maka variabel dependen yaitu Profitabilitas (ROA) akan naik sebesar 7,092\%.

2. Koefisien variabel CAR $=0,016$ dengan arah negatif, berarti setiap kenaikan CAR sebesar $1 \%$ akan menyebabkan penurunan Profitabilitas (ROA) sebesar 0,016\%.

3. Koefisien $L D R=0,040$ dengan arah negatif artinya jika LDR mengalami kenaikan sebesar $1 \%$ maka profitabilitas (ROA) akan menurun sebesar $0,040 \%$.

4. koefisien variabel $\mathrm{BOPO}=0,39$ dengan arah negatif artinya jika BOPO mengalami kenaikan sebesar 1\%, maka profitabilitas (ROA) akan menurun sebesar 0,39\%.

5. Koefisien NIM sebesar 0,371 dengan arah positif menunjukkan bahwa setiap terjadi kenaikan NIM sebesar 1\% maka profitabilitas (ROA) akan naik sebesar 0,371\%.

\section{Koefisien Determinasi}

Dalam analisis korelasi terdapat suatu angka yang disebut dengan koefisien determinasi atau yang sering disebut dengan koefisien penentu, karena besarnya adalah kuadrat dari koefisien korelasi $\left(\mathrm{r}^{2}\right)$, sehingga koefisien ini berguna untuk mengetahui besarnya pengaruh variabel $\mathrm{X}$ terhadap variabel Y.

Tabel 11

\section{Koefisien Determinasi}


Model Summary ${ }^{b}$

\begin{tabular}{|c|c|c|c|c|}
\hline Model & $\mathrm{R}$ & $\begin{array}{c}\mathrm{R} \\
\text { Square }\end{array}$ & $\begin{array}{c}\text { Adjusted } \\
\text { R } \\
\text { Square }\end{array}$ & $\begin{array}{c}\text { Std. Error of the } \\
\text { Estimate }\end{array}$ \\
\hline 1 & $.899^{\mathrm{a}}$ & .808 & .791 & .53880 \\
\hline
\end{tabular}

a. Predictors: (Constant), NIM, LDR, CAR,

BOPO

b. Dependent Variable: ROA

Sumber: SPSS 22 (data diolah 2017)

Berdasarkan tabel di atas, menunjukan bahwa koefisien determinasi $\left(\mathrm{R}^{2}\right)$ sebesar 0,808 atau $80,8 \%$, maka variabel Profitabilitas yang diproksikan dengan (Y) bisa diterangkan oleh variabel CAR $\left(\mathrm{X}_{1}\right)$, LDR $\left(\mathrm{X}_{2}\right)$, BOPO $\left(\mathrm{X}_{3}\right)$ dan NIM $\left(\mathrm{X}_{4}\right)$ atau dapat diartikan CAR $\left(\mathrm{X}_{1}\right)$, LDR $\left(\mathrm{X}_{2}\right)$, BOPO $\left(\mathrm{X}_{3}\right)$ dan NIM $\left(\mathrm{X}_{4}\right)$ berpengaruh terhadap Profitabilitas yang diproksikan dengan ROA (Y) sebesar $80,8 \%$ sedangkan sisanya 19,2\% merupakan pengaruh dari faktor lain yang tidak diteliti.

\section{Pengaruh CAR Terhadap Profitabilitas}

Pengaruh CAR terhadap profitabilitas dapat diketahui melalui pengujian statistik dengan

hipotesis sebagai berikut:

Hipotesis Statistik:

$\mathrm{H} 0: \mathrm{b}_{1} \mathrm{X}_{1}=0$ (tidak ada pengaruh)

Ha: $b_{1} X_{1} \neq 0$ (ada pengaruh)

Hipotesis bentuk kalimat:

H0: Capital Adequacy Ratio tidak berpengaruh terhadap Profitabilitas

Ha: Capital Adequacy Ratio berpengaruh terhadap Profitabilitas

Berdasarkan Uji t didapatkan koefisien pengaruh CAR terhadap Profitabilitas adalah - 0,417 dengan nilai sig $=0,679>0,05$. Hal Ini menunjukan CAR secara parsial berpengaruh tidak signifikan dan berkontribusi negatif terhadap profitabilitas. Yang berarti bahwa semakin tinggi CAR maka akan semakin rendah profitabilitas (ROA) perbankan tersebut.

\section{Pengaruh LDR Terhadap Profitabilitas}

Hipotesis Statistik:

$\mathrm{H} 0: \mathrm{b}_{2} \mathrm{X}_{2}=0$ (tidak ada pengaruh)

Ha: $b_{2} X_{2} \neq 0$ (ada pengaruh)

Hipotesis bentuk kalimat:

H0: Loan to Deposit Ratio tidak berpengaruh terhadap Profitabilitas

Ha: Loan to Deposit Ratio berpengaruh terhadap Profitabilitas

Berdasarkan Uji t didapatkan koefisien pengaruh LDR terhadap profitabilitas adalah -3.871 dengan nilai sig $=0,000<0,05$. Ini menunjukan bahwa LDR secara parsial berpengaruh negatif dan signifikan terhadap profitabilitas (ROA). Hal ini berarti semakin tinggi LDR maka akan semakin rendah profitabilitas (ROA) perbankan tersebut.

\section{Pengaruh BOPO Terhadap Profitabilitas}

Hipotesis Statistik:

$\mathrm{H} 0: \mathrm{b}_{3} \mathrm{X}_{3}=0$ (tidak ada pengaruh)

Ha: $b_{3} X_{3} \neq 0$ (ada pengaruh) 
Hipotesis bentuk kalimat:

H0: BOPO tidak berpengaruh terhadap Profitabilitas

Ha: BOPO berpengaruh terhadap Profitabilitas

Berdasarkan Uji t didapatkan pengaruh BOPO terhadap profitabilitas adalah -5.928 dengan nilai sig $=0,000<0,05$. Ini menunjukan bahwa BOPO secara parsial berpengaruh negatif dan signifikan terhadap profitabilitas (ROA). Hal ini berarti bahwa semakin tinggi BOPO maka akan semakin rendah profitabilitas (ROA) perbankan tersebut.

\section{Pengaruh NIM Terhadap Profitabiitas}

Hipotesis Statistik:

$\mathrm{H} 0 \quad: \mathrm{b}_{4} \mathrm{X}_{4}=0$ (tidak ada pengaruh)

$\mathrm{Ha}: \mathrm{b}_{4} \mathrm{X}_{4} \neq 0$ (ada pengaruh)

Hipotesis bentuk kalimat:

H0: Net Interest Margin tidak berpengaruh terhadap Profitabilitas

Ha: Net Interest Margin berpengaruh terhadap Profitabilitas

Berdasarkan Uji t didapatkan koefisien pengaruh NIM terhadap profitabilitas adalah 5,654 dengan nilai sig $=0,000<0,05$. Hal Ini menunjukan bahwa NIM secara parsial berpengaruh positif dan signifikan terhadap profitabilitas (ROA). Hal ini berarti bahwa semakin tinggi NIM maka akan semakin tinggi profitabilitas (ROA) perbankan tersebut.

\section{Pengaruh Simultan CAR, LDR, BOPO dan NIM Terhadap Profitabilitas}

Uji F (F-test) dimaksudkan untuk mengetahui pengaruh variabel-variabel independen (CAR, LDR, BOPO dan NIM) secara simultan (bersama-sama) terhadap profitabilitas (ROA) perbankan yang terdaftar di Bursa Efek Indonesia periode 2012-2016.

Hipotesis statistik:

H0 : $b_{1}, 4=0$ (tidak ada pengaruh)

$\mathrm{Ha}: b_{1}, 4 \neq 0$ (ada pengaruh)

Hipotesis bentuk kalimat:

H0: Capital Adequacy Ratio, Loan to Deposit Ratio, BOPO dan Net Intetest

Margin secara simultan tidak berpengaruh terhadap Profitabilitas

Ha: Capital Adequacy Ratio, Loan to Deposit Ratio, BOPO dan Net Intetest Margin secara simultan berpengaruh terhadap Profitabilitas

Dengan kriteria ujinya sebagai berikut:

1) $\mathrm{H}_{0}$ ditolak jika sig $<\alpha$ atau $\left|\mathrm{F}_{\text {hitung }}\right| \geq \mathrm{F}_{\text {tabel }}$ dengan taraf signifikasi $5 \%$ maka pengujian signifikan atau ada pengaruh nyata dari masing-masing $\mathrm{x}_{1}, \mathrm{x}_{2}, \mathrm{x}_{3}$ dan $\mathrm{x}_{4}$, atau setidaknya terhadap variabel terikat $\mathrm{Y}$.

2) $\mathrm{H}_{0}$ diterima sig $>\alpha$ atau $\left|\mathrm{F}_{\text {hitung }}\right|<\mathrm{F}_{\text {tabel }}$ dengan taraf signifikasi $5 \%$ maka pengujian tidak signifikan atau tidak ada pengaruh nyata dari masing-masing $\mathrm{x}_{1}, \mathrm{x}_{2}, \mathrm{x}_{3}$ dan $\mathrm{x}_{4}$ terhadap variabel terikat Y. Hasil uji simultan dengan SPSS 22 disajikan pada tabel dibawah ini:

\section{Tabel 12}

\section{Hasil Uji F}


ANOVA $^{b}$

\begin{tabular}{|ll|r|r|r|r|r|}
\hline Model & & \multicolumn{1}{|c|}{$\begin{array}{c}\text { Sum of } \\
\text { Squares }\end{array}$} & Df & $\begin{array}{c}\text { Mean } \\
\text { Square }\end{array}$ & F & \multicolumn{1}{c|}{ Sig. } \\
\hline 1 & Regression & 54.923 & 4 & 13.731 & 47.298 & $.000^{\mathrm{a}}$ \\
& & & & & \\
& Residual & 13.064 & 45 & .290 & & \\
& Total & 67.987 & 49 & & & \\
\hline
\end{tabular}

a. Predictors: (Constant), NIM, LDR, CAR, BOPO

b. Dependent Variable: ROA

Sumber: SPSS 22 (data Diolah 2017)

Berdasarkan Tabel 4.7 di atas, menunjukan bahwa $F_{\text {hitung }}=47,298$ sig. 0,000. Pengaruh $X_{1}, X_{2}$, $\mathrm{X}_{3}$ dan $\mathrm{X}_{4}$ secara simultan terhadap $\mathrm{Y}$ diperlihatkan pada tabel 4.9 di bawah ini:

\section{Tabel 13}

Pengaruh Simultan CAR $\left(\mathrm{X}_{1}\right)$, LDR $\left(\mathrm{X}_{2}\right)$, BOPO $\left(\mathrm{X}_{3}\right)$ dan NIM $\left(\mathrm{X}_{4}\right)$ terhadap Profitabilitas (Y)

\begin{tabular}{|c|c|c|c|c|c|}
\hline Structural & Sig. & A & F $_{\text {hitung }}$ & F $_{\text {tabel }}$ & Kesimpulan \\
\hline Pyx $_{1} \mathrm{x}_{2}$ & 0,000 & 0,05 & 47,298 & 2,53 & $\mathrm{H}_{\mathrm{o}}$ ditolak \\
\hline
\end{tabular}

Sumber: SPSS 22 (Data Diolah 2017)

Tabel menunjukan bahwa nilai sig. $(0,000)<\alpha(0,05)$ dan $F_{\text {hitung }}(47,298)>F_{\text {tabel }}(2,53)$ maka $\mathrm{H}_{\mathrm{o}}$ ditolak. Dengan demikian dapat disimpulkan bahwa CAR, LDR, BOPO dan NIM secara simultan berpengaruh positif dan signifikan terhadap Profitabilitas (ROA) Perbankan pada periode penelitian.

\section{F. SIMPULAN}

Berdasarkan hasil analisis dan pembahasan yang telah dikemukakan pada bab sebelumnya, maka dapat ditarik kesimpulan sebagai berikut:

1. Profitabilitas Bank Umum konvensional selama periode penelitian memiliki rata-rata sebesar $2,46 \%$ yaitu pada kategori sangat sehat karena berada diatas $1,5 \%$. Hal ini menunjukkan bahwa bank umum konvensional pada periode penelitian memiliki kinerja yang baik karena perusahaan telah mampu memanfaatkan dengan baik investasi yang telah ditanamkan (asset yang dimilikinya) untuk mendapatkan laba.

2. Rasio CAR Bank Umum konvensional pada periode penelitian dengan rata-rata $17,34 \%$ dikategorikan sangat sehat karena berada di atas standar minimum yang ditetapkan Bank Indonesia yaitu 8\%. Hal ini disebabkan karena bank lebih menjaga kecukupan modal dalam melaksanakan kegiatan operasionalnya, karena Dengan terpenuhinya CAR oleh bank maka bank tersebut dapat menyerap kerugian-kerugian yang dialami, sehingga kegiatan yang dilakukan akan berjalan secara efisien.

3. Rasio LDR Bank Umum konvensional selama periode penelitian memiliki nilai rata-rata $89,31 \%$ dikategorikan cukup baik. Hal tersebut menunjukkan bahwa semakin rendahnya likuiditas Bank umum konvensional karena jumlah dana dari masayarakat yang disalurkan ke kredit terlalu besar.

4. Rasio BOPO Bank Umum konvensional selama periode penelitian memiliki nilai mean $75,54 \%$ artinya secara statistik rasio BOPO Bank Umum konvensional selama periode penelitian dikategorikan sangat sehat karena berada dibawah 94\%. Hal ini disebabkan karena bank terus berusaha untuk melakukan efisiensi terhadap beban operasional agar dapat meningkatkan laba yang diharapkan. 
5. Rasio NIM memiliki nilai rata-rata 5,81\% yang berarti secara statistik rasio NIM Bank Umum konvensional selama periode penelitian dikategorikan sangat sehat karena berada di atas 3\%. Hal ini disebabkan bank telah mampu meningkatkan serta memaksimalkan pendapatan bunga, secara keseluruhan rata-rata rentabilitas bank sangat memadai untuk mendukung pertumbuhan permodalan bank

6. CAR secara parsial berpengaruh tidak signifikan dan berkontribusi negatif terhadap profitabilitas (ROA) Bank Umum konvensional pada periode penelitian dengan koefisien $-0,417$, yang berarti bahwa semakin tinggi CAR maka akan semakin rendah profitabilitas (ROA) perbankan tersebut. Sedangkan LDR dan BOPO secara parsial berpengaruh negatif dan signifikan terhadap profitabilitas (ROA), dengan koefisien masing-masing -3,871 dan -5,928, yang berarti bahwa dimana semakin tinggi LDR dan BOPO maka Profitabilitas (ROA) perbankan akan semakin rendah. BOPO merupakan variabel yang memiliki pengaruh paling besar terhadap Profitabilitas diantara Variabel lain. Sementara NIM secara parsial berpengaruh positif dan signifikan terhadap profitabilitas (ROA) dengan nilai koefisien 5,654. Yang berarti bahwa semakin tinggi NIM maka profitabilitas (ROA) perbankan akan semakin tinggi.

7. CAR, LDR, BOPO dan NIM secara simultan berpengaruh positif dan signifikan terhadap Profitabilitas (ROA) Perbankan pada periode penelitian. Dengan koefisien sebesar 47,298.

\section{G. SARAN}

Berdasarkan hasil kesimpulan diatas, maka dapat disampaikan saran yang bermanfaat bagi perusahaan antara lain:

1. Diharapkan bank umum konvensional dapat terus meningkatkan profitabilitas (ROA) untuk kelangsungan hidup perusahaan.

2. Diharapkan bank umum konvensional terus menjaga agar CAR tidak terlalu tinggi dari batas yang distandarkan Bank Indonesia karena jika terlalu tinggi maka modal yang ada tidak dapat dipergunakan secara optimal.

3. Diharapkan bank umum konvensional terus menjaga tingkat likuiditasnya dengan baik agar perusahaan dapat menutupi seluruh hutang-hutangnya baik jangka pendek ataupun jangka panjang.

4. Diharapkan bank umum konvensional terus menjaga BOPO supaya tidak semakin meningkat agar dapat lebih efisien dalam menjalankan kegiatan operasionalnya.

5. Diharapkan bank umum konvensional terus menekan NIM agar tidak terlalu tinggi dan melebihi standar yang ditetapkan Bank Indonesia.

6. Diharapkan bank umum konvensional untuk terus menjaga CAR, LDR,BOPO dan NIM agar sesuai dengan standar Bank Indonesia sehingga profit yang didapatkan semakin maksimal.

7. Adapun kajian atau penelitian lebih lanjut agar ditambahkan variabel lain yaitu NPL (Non Performing Loan) sehingga dapat diketahui pengaruhnya terhadap Profitabilitas pada Bank Umum Konvensional.

\section{H. DAFTAR PUSTAKA}

\section{Buku Dan Jurnal}

Abd. Hamid Habbe, Ali, Sabir, 2012. Pengaruh Rasio Kesehatan Bank Terhadap Kinerja Keuangan

Bank UmumSyariah Dan Bank Konvensional Di Indonesia. Jurnal. (Diakses Tanggal 03 April 2017, 03:53)

Brigham dan Houston, 2010. Dasar-Dasar Manajemen Keuangan Buku 1. Edisi ke Sebelas,Jakarta: 
Salemba Empat.

Dendawijaya, Lukman. 2009. Manajemen Perbankan. Jakarta: Ghalia Indonesia

Dwi Priyatno. 2010. Teknik Mudah dan Cepat Melakukan Analisis Data Penelitian dengan SPSS dan

Tanya Jawab Ujian Pendadaran. Penerbit Gaya Media. Yogyakarta.

Fahmi, Irham, 2011. Analisis Kinerja Keuangan. Edisi ke Satu, Bandung: Alfabeta.

Ghozali, Imam. 2011. "Aplikasi Analisis Multivariate Dengan Program SPSS". Semarang: Badan

Penerbit Universitas Diponegoro.

Ismail. 2015. Akuntansi Bank Teori dan Aplikasi Dalam Rupiah. Jakarta: Prenamedia Group Jonathan Sarwono. Metode Penelitian Kuantitatif dan Kualitatif. Yogyakarta: Graha Ilmu.

Hayati Nur, Musdholifah. 2014. Determinan Profitabilitas Perbankan Nasional Di Indonesia. Jurnal.

(DiaksesTanggal 17 April 2017, 12:07)

Kamaludin, 2011. Manajemen Keuangan. Bandung: CV. Mandar Maju

Kasmir, 2010. Pengantar Manajemen Keuangan. Kencana Prenada Media Jakarta: Group.

Manullang, Marihot dan Dearlina Sinaga, 2005. Pengantar Manajemen Keuangan. Penerbit Andi.

Yogyakarta: Edisi Pertama.

Martani, Dwi dkk, 2015. Akuntansi Keuangan Menengah Berbasis PSAK, PSAK Konfegrensi IFRS,

Jakarta: Salemba Empat.

Mashuri, M Zanudin. 2009. Metode Penelitian: Pendekatan Praktis dan Aplikatif. Bandung: Refika

Aditama.

Mawaddah, Nur, 2015. Faktor-Faktor Yang Mempengaruhi Profitabilitas Bank Syariah. Jurnal.

(DiaksesTanggal 3 April 2017, 02:33)

Pranata Dwi Wahyu Alit A.A. 2015. Pengaruh Capital Adequacy Ratio, Loan To Deposit Ratio Dan

Ukuran Perusahaan Pada Profitabilitas Bank Di Bursa Efek Indonesia. Jurnal. (DiaksesTanggal 3 April 2017, 08:58)

Purnamawati Ayu IG. 2014. The Effect Of Capital And Liquidity Risk To Profitability On Conventional

Rural Bank In Indonesia. Jurnal. (DiaksesTanggal 17 April 2017, 04:21).

Prawironegoro, Darsono dan Ari Purwanti. (2009). Akuntansi Manajemen. Edisi

Ketiga, Jakarta: Mitra Wacana Media.

Prihadi, Toto, 2008. Analisis Rasio Keuangan. PPM Manajemen, Jakarta.

Riyadi, Slamet. 2006. Banking Asset and Liability Mangement. Edisi Ketiga. Lembaga Penerbit

Fakultas Ekonomi Universitas Indonesia.

Riyanto, Bambang, 2010. Dasar-dasar Pembelanjaan Perusahaan. Cetakan Kesepuluh. Yogyakarta:

BPFE.

Robbins, Stephen P \& Mary Coulter, 2010. Manajemen Edisi 10. Penerbit Erlangga, Jakarta. Sartono, Agus R, 2008. Manajemen Keuangan Teori dan Aplikasi. Edisi ke Empat, Yogyakarta: BPFE.

Sofyan Syafri Harahap. (2011). Analisis Kritis Atas Laporan Keuangan. Jakarta: Raja grafindo Persada

Sugiyono, 2011. Metode Penelitian Kuantitatif, Kualitatif, dan $R \&$ D. Penerbit Bandung: Alfabeta. 
Sule, Ernie Tisnawati dan Kurniawan Saefullah, 2010. Pengantar Manajemen Edisi 1. Jakarta: Kencana Prenada Media Group.

Sutrisno. 2008. Manajemen Keuangan (Teori, Konsep, dan Aplikasi).Yogyakarta: Penerbit Ekonisi.

Sumiati, Dj Hadiwidjojo, Alindra Yanuardi. 2014. Faktor Determinan Atas Profitabilitas Perbankan

Yang Terdaftar Di Bursa Efek Indonesia. Jurnal. (DiaksesTanggal 3 April 2017, 02:58)

Sony Warsono-bin-Hardono dkk, 2013. Akuntansi Pengantar 1, Adaptasi IFRS. Yogyakarta: $\mathrm{AB}$

Publisher.

Syamsudin, Lukman. 2011. Manajemen Keuangan Perusahaan. Jakarta: Rajawali Pers

Tan Sau Eng. Pengaruh Nim, Bopo, Ldr, Npl \& Car Terhadap Roa Bank Internasional Dan Bank

Nasional Go Public Periode 2007 - 2011. Jurnal. (DiaksesTanggal 18 Maret 2017,

Taswan. 2010. Akuntansi Perbankan Transaksi dalam Valuta Rupiah. UPP STIM Yogyakarta: YKPN

YKPN

2013. Akuntansi Perbankan Transaksi dalam Valuta Rupiah. UPP STIM Yogyakarta:

Van Horne, James C. Dan John M. Wachowicz, Jr, 2012. Prinsip-Prinsip Manajemen Keuangan. Edisi

ke Tigabelas, Jakarta: Salemba Empat.

Warsa Putri Utami IMN, Mustanda Ketut. 2016. Pengaruh CAR, LDR Dan NPL Terhadap ROA Pada 03:26)

Sektor Perbankan Di Bursa Efek Indonesia. Jurnal. (DiaksesTanggal 6 April 2017,

Yudiartini Sri DA, IB Dharmadiaksa, 2016. Pengaruh Rasio Keuangan Terhadap Kinerja Keuangan

Sektor Perbankan Di Bursa Efek Indonesia. Jurnal. (DiaksesTanggal 3 April 2017, 04:10)

\section{Peraturan, Kebijakan dan Buku Pedoman}

1. Undang-Undang Negara Republik Indonesia Nomor 10 Tahun 1998 tentang perbankan

2. Surat Edaran Otoritas Jasa Keuangan Nomor 11/Seojk.03/2015

III. Sumber Website

1. http://www.idx.co.id (Diakses Tanggal 3 April 2017, 14:10)

2. www.ojk.go.id (Diakses Tanggal 03 April 2017, 12:30)

3. www.google.com

4. www.wikipedia.org/wiki/Likuiditas 2017 (Diakses 03 April 2017, 12:35)

5. www.qaribaz.blogspot.com 